\section{Gramáticas actuales de la relación hombre-trabajo. Propuestas de lectura}

Editorial Bonaventuriana, Universidad de San Buenaventura Cali

Autores: Sigmar Malvezzi

Johnny Javier Orejuela

Rafael Marcus Chiuzi

Juan Javier Vesga

Wilner Riascos

Año: 2012

Número de páginas: 131

Por: Andrés Caballero

El trabajo, tan decisivo en el estilo y en la calidad de vida (o por lo menos así aparece en el imaginario colectivo) es algo para lo cual se nos prepara; es la meta de un tipo particular de educación: la profesionalizante. El trabajo se encuentra estrechamente relacionado con los cambios tecnológicos, las políticas de desarrollo y las perspectivas económicas de un país en vías de desarrollo.

A partir de sus complejidades el significado del trabajo no puede comprenderse si no se estudia de manera conjunta con su complemento: el recurso o talento humano. $\mathrm{Y}$ es este, precisamente, el objetivo de presente libro trazado bajo la óptica de la relación hombre-trabajo y sus implicaciones subjetivas.

En el texto se analizan las diferentes concepciones de trabajo con base en sus transformaciones culturales, económicas y sociales. Se aduce que fenómenos como la globalización han implicado rupturas históricas (de la Revolución Industrial a la revolución tecnológica) e influido en las políticas

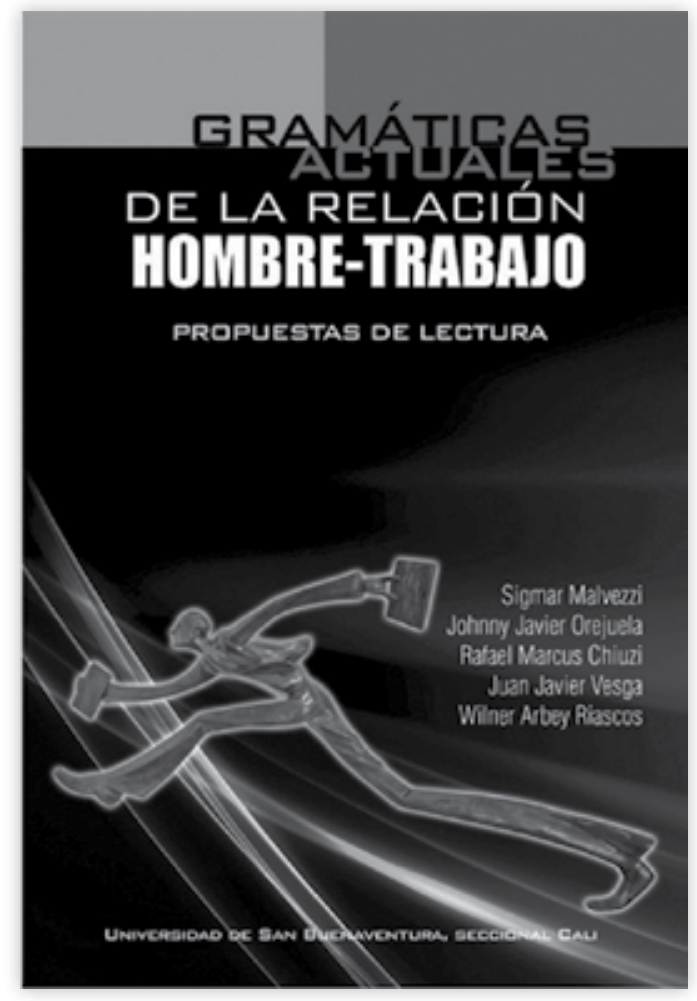

educativas, los planes de desarrollo y sistemas de financiación y en los planes de endeudamiento sistemático, en los cuales se hipoteca el "yo ideal" para cubrir los costos del "ideal del yo".

Este libro permite lecturas diversas de las coordenadas que determinan el paisaje laboral contemporáneo y los conceptos de trabajo, así como el abordaje de este a partir de la subjetividad. La persona que ejecuta el trabajo es un ser subjetivo y vierte en esta actividad sus metas, sus aspiraciones, sus miedos y sus creencias, puesto que su proyección en la vida es función directa de su mundo laboral. Esto se trasluce en sus relaciones con la organización, en la forma como construye sus diferentes identidades, en las diferentes maneras de ser y en las diversas formas de actuar en el mundo.

Los autores abordan la relación entre el hombre y el trabajo sobre la base de ponderar las distintas realidades y subjetividades interconectadas con este último y profundizar en las diferentes representaciones que los sujetos hacen del mundo laboral.

ANDRÉS CABALLERO. Integrante del Grupo de Investigación en Evaluación y Calidad de la Educación (GIECE). Estudiante de Psicología de la Universidad de San Buenaventura Cali. Correo electrónico: andres.caballero92@gmail.com 
Se plantea asimismo, la relación formal entre el trabajador y la empresa establecida en el contrato de trabajo a fin de debatir las expectativas que dicho acuerdo genera.

La psicología del trabajo y de las organizaciones debe dialogar con otras disciplinas a fin de ampliar su discurso y configurar el campo a partir de las múltiples variables que intervienen en el mundo laboral, para lo cual los autores proponen hablar de trabajo y sociedad y de persona y organización, al tiempo que plantean el diseño de estrategias interdisciplinarias para investigar e intervenir con base en lo subjetivo y a partir de ahí promover nuevos paradigmas que integren lo ético y lo moral, tema de actualidad (mas no ignorado) que refresca los hechos que han dado origen a las visiones modernas acerca del trabajo.

El libro es igualmente, una aproximación a la subjetividad y a los desafíos que esta plantea para la investigación en la era de las empresas-red y cómo se refleja en la relación hombre-trabajo-sociedad. En el texto también se analizan aspectos como la rutina, el determinismo de la tecnología, el manejo de las emociones y la negociación de los contratos psicológicos.

La reconfiguración de la sociedad actual, las nuevas maneras de relacionarse y la heterogeneidad, conllevan una individuación del trabajo cada vez más aguda y acrecientan los síntomas de sufrimiento subjetivo, además de exigir el cumplimiento de metas sin contar con los suficientes recursos para lograr este fin, amén de una poca autoexigencia y una jerarquización a menudo asfixiante. A su turno la fragmentación laboral en la relación hombre-trabajo produce diferentes formas de afrontar este último, de plantearse objetivos y de sentirse competente o incompetente.

Las condiciones de incertidumbre laboral influyen en el goce, en el sufrimiento y en los ima- ginarios y es a partir de este punto que el contrato psicológico juega un papel central. El contrato psicológico son las representaciones y gramáticas que alimentan el imaginario de las personas y surge a partir de las relaciones sociodiscursivas entre los sujetos. Se trata de una visión que concibe el trabajo unido a las expectativas, a las metas y a las creencias del trabajador en torno a la organización, lo cual rebasa sobradamente aquello que dicta el simple articulado de un documento formal.

Es fundamental reflexionar sobre lo que el sistema globalizado actual produce en el mundo laboral, examen que debe hacerse de la mano de diversas disciplinas que aborden múltiples puntos de vista en lo que toca a la relación hombre-trabajo-sociedad, relación claramente mediada por las configuraciones y los discursos sociales.

Vale la pena preguntarse por la articulación de la educación con el mundo productivo, lo que el Ministerio de Educación Nacional ha denominado "formación de competencias laborales" o políticas de emprendimiento. ¿Qué se pretende con "adecuar a los trabajadores a las nuevas exigencias del mercado y aumentar la empleabilidad de la fuerza laboral en su conjunto"? ¿Acaso el propósito de la educación no se subvierte y se deja de lado la "educación dirigida a pensar y reflexionar" a cambio de una educación que tiene como propósito la "articulación de la oferta educativa con el mundo productivo"?, son las preguntas que este libro provoca en los lectores.

Para terminar, este estudio es relevante ya que aborda las diversas realidades que trascienden lo estrictamente laboral para adentrarse en las múltiples dimensiones de la vida de las personas. Es una lectura que resulta sugestiva y oportuna para quienes tienen que ver con el mundo laboral, el mundo académico y, por qué no, el mundo en general. 